\title{
DETERMINATION OF FORMAL SIGNS FOR INDICATORS OF EFFICIENCY EVALUATION OF CONTROLLED SYSTEMS OPERATIONS
}

\author{
Olga Serdiuk \\ Department of computer systems and networks \\ SIHE «Kryvyi Rih National University», \\ 11 XXII Partzizdu str., Kryvyi Rih, Ukraine, 50027 \\ olgajs28@gmail.com
}

\begin{abstract}
Research connected with studying of efficiency assessment possibility of system operation simple model using its general model parameters and establishing of operation general model objects as efficiency formula's formal signs is presented in the article.

To conduct research, model of controlled system was created, structure of which is implemented as software product. Peculiarity of this model is possibility of carrying out experimental study, as result of which it is possible to detect changes in parameters of number of system operations under different control regimes.

As result of research, it was established that it is impossible to make comparative assessment between operations, which conducted in different control regimes, applying quantitative characteristics of input and output operational process parameters.

During creation of converting class system model structure, concept of operation reduction to its simple general model has been used. Model of program designer provides integration of cost parameters of input and output products by means of which, opportunity for efficiency determination of operations, functioning at different control modes is investigated. Analysis of operational process estimation results has shown that operation general model objects are formal signs of operations efficiency formula.

Different modes of optimum control to which have pointed extrema of several indicators have revealed absence problem systemically reasonable verification method of applied estimated indicators regarding their use as optimization criterion.

Practical importance of this research is that using presented program designer of controlled system and cybernetic approach allow apply results of research on all types of controlled systems. It promotes the optimization issue solution in finding of optimum mode of executive systems functioning and obtaining maximum economic effect of enterprise.
\end{abstract}

Keywords: formal signs of performance indicators, operation general model, controlled system, efficiency criterion.

\section{Introduction}

Maximization of pace of modern enterprise development can be reached only if procedural activity of each controlled system which is its part works with maximum resources efficiency. This is possible in the case of using only one systematically valid efficiency indicator as optimization criterion.

The scientific problem consists that many estimated indicators, which are used as optimization criteria, aren't systemically reasonable. And also at the moment the formal signs, to which the resources efficiency indicator have to correspond, aren't defined.

The work is devoted to issue of formal signs determination of efficiency calculation general estimated indicator for controlled systems operations simple models.

\section{Review of the problem statement}

The relevance of finding and verification of resources efficiency indicator is explained by the fact that its application, for example, as an optimization criterion, allows to increase sharply rates of economic structure development and, therefore, its competitiveness as well [1-3].

Thus, the problem of finding or developing an indicator, which really solves the issue of operational processes efficiency evaluating with maximum accuracy, is arose [4-6].

In solution of question of any activity assessing, the indicators, reflecting only one of parts of operation under investigation still have been used [7-10].

For a comparative evaluation of processes functioning, the authors traditionally introduce a number of estimated indicators and indicators of quality control, each of which determines one or another side of these processes [11]. If applying of indicators is related to control, then it is necessary to distinguish the category of indicators directly related to cybernetics $[12,13]$. 
To solve the technical and economic optimization issues, the methods of multiple-criteria decision analysis are actively used [14]. At the same time, there is no justification for the made decision on the best variant of studied object functioning, using this approach.

As a result, the estimated criteria have the most various internal structures which don't reflect the cybernetics of studied process [15].

So the problem of determination of efficiency criterion formal signs for simple operations estimation is relevant and important task on today.

\section{Materials and methods of research}

Development of method to assessment of operational process demands the carrying out of researches connected with identification of general principles of comparison of input and output operation products. In that case researches are conducted with use of real or model system, and then results are generalized on all class of similar objects.

As an object of research the process of portion liquid heating with use of electric heater is chosen.

Such choice is connected with the fact that the model of controlled heating process, which has the access to necessary data, has been realized in the program designer EFFLI [16] (Fig. 1).

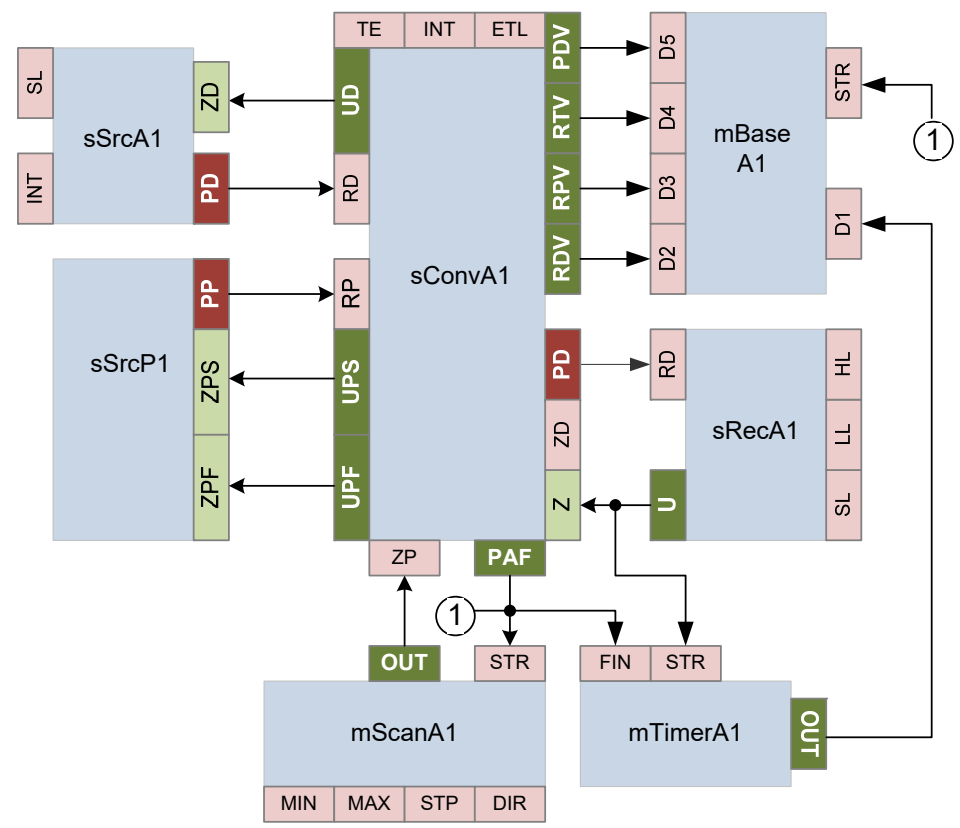

Fig. 1. Model of technological controlled system

Where: sSrcA1 - source of product of directed action of limited power; sSrcP1 - source of energy product of unlimited power; sConvA1 - heating system; mBaseA1 -database; sRecA1 receiver of products of limited power; mScanAlst mechanism of scanning of range of admissible controls; mTimerA1 - timer; INT - section of setting of output product intensity; SL - section of setting of first stock level; PD - section of finished product output; PP - section of energy product output; PAF - section of output about operation completion signal; PDV - section for issuing information about volume of main source product; RD - section of receiving product of directed action; $\mathrm{RP}$ - section of energy product receiving; RDV - section for issuing information about volume of input product of directed action; RPV - section for issuing information about energy consumption volume; RTV - section for issuing information about heating mechanism wear; TE - ambient temperature setting section; $Z$ - section for receiving reference signal at beginning of system operation active phase; $\mathrm{ZP}$ - setting section of energy product intensity; ZD - volume setting section of product of directed action; ZPF - signal receiving section for stopping of energy product supply; ZPS - signal receiving section to start energy product supply; U - control signal output section; UD - section of output of control of task volume of product of directed action; UPS - signal feed-in 
section to start energy product supply; UPF - signal feed-in section to stop energy product supply; D1-D4 - data entry sections; STR - signal reception section at the beginning of the active phase of mechanism operation ; SL - section of start stock level setting; LL - low level stock section; $\mathrm{HL}$ - section of setting of top stock level; MIN - task section for first control; MAX - section of finish control setting; STP - task section to stops signs after scanning of range of controls; DIR - task section of direction of scanning of controls range; OUT - section of output of created information product; STP - section to set step of control change; FIN - section of signal to finish the active phase of mechanism operation.

This software product is the specialized environment and is intended to study the research of results of procedural activity of online interacting systems.

The object model of heating system is presented in the form of EFFLI objects in Fig. 1. The working model is available according to the link [17].

Model objects are in interactive contact among themselves by means of exchange of information products with use of port sections. Each section is nominal and is intended for reception or output of a certain information product.

Sections of two interacting objects form a channel. Further, according to the text, sections and channels are defined in square brackets.

Preparation of the system for investigation consists in setting of the necessary initial parameters, the values of which are given in Table 1.

Table 1

The value of start settings of model of technical controlled system

\begin{tabular}{ccc}
\hline Object & Section & Value \\
\hline sSrcA1 & INT & 0,01 \\
sSrcA1 & SL & 40 \\
sConvA1 & TE & 20 \\
sConvA1 & INT & 0,01 \\
sConvA1 & ETL & 50 \\
sConvA1 & ZD & 1 \\
sRecA1 & SL & 0 \\
sRecA1 & LL & 2 \\
sRecA1 & HL & 40 \\
mScanA1 & MIN & 30 \\
mScanA1 & MAX & 75 \\
mScanA1 & STP & 5 \\
mScanA1 & DIR & 0
\end{tabular}

The principle of system functioning (Fig. 1) is presented below.

If, at the time of the launch, the initial level of stocks that is reflected in the [SL] section of output product sRecA1 receiver is less than the lower level, a high level control signal is generated in its section [U]. This signal is transmitted to the task section [Z] of the sConvA1 heating system and to the [STR] section of mTimerA1 timer.

After receiving the reference signal, the liquid heating system reads the reference signal in the [ZD] section. This section of the port contains information on the required value of cold water supply.

The information received from the [ZD] section is transmitted via the [UD-ZD] channel from the liquid heating system to sSrcA1 source, after which the sSrcA1 source transmits the cold liquid through the [PD-RD] channel to heating system with intensity that is set in the [INT] section source. 
When the cold water supply operation is completed, the heating system generates a signal for the start of power supply via the [UPS-ZPS] channel. The intensity of energy supply to the [ZP] section transmits the mScanA1 mechanism via the [OUT-ZP] channel.

In the [OUT] section of mScanA1 mechanism, at the initial stage of start-up, the minimum intensity level of the energy product is set.

From the moment of energy product is fed, the process of liquid heating starts, which continues until the liquid temperature reaches the level specified in [ETL] section. At this point in time, the heating system generates control signal to terminate the supply of energy product. This signal is transmitted via the [UPF-ZPF] channel to input of power supply system.

At the same time, the main product (heated liquid) is dispensed via [PD-RD] channel. The intensity of output of the main product is determined by the value of information product in section [INT] of the sConvA1 system.

When the main product is being dispensed, the sConvA1 system issues an information signal for the completion of heating operation, which is transmitted to the [PAF] section.

On channels [PAF-STR], the information signal for the heating operation completion is sent to mBaseA1 database and to scanner of range of admissible controls mScanA1, and on channel [PAF-STP] to input of timer mTimerA1.

At the same time, the operation time is transferred to the mBaseA1 database via the [OUT-D1] channel, [OUT-D2] - the amount of consumption of the directed effect product, [OUT-D3] - the volume of the consumed energy product, via the channel [OUT-D4], the wear level is transmitted and information on the volume of main product is transmitted via the channel [OUT-D5].

The input of operation completion information signal to the [STR] section of the control scanner changes the level of the intensity of the energy product supply by the step size that is set in the $[\mathrm{STP}]$ section.

\section{Experimental procedures}

4. 1. Analysis of changes in the system operations quantitative parameters depending on different control regimes

As result of the research, the data, allowing estimate the change in all important parameters at the input and output of the controlled system (Fig. 2) and also operation time dependence on control are obtained.

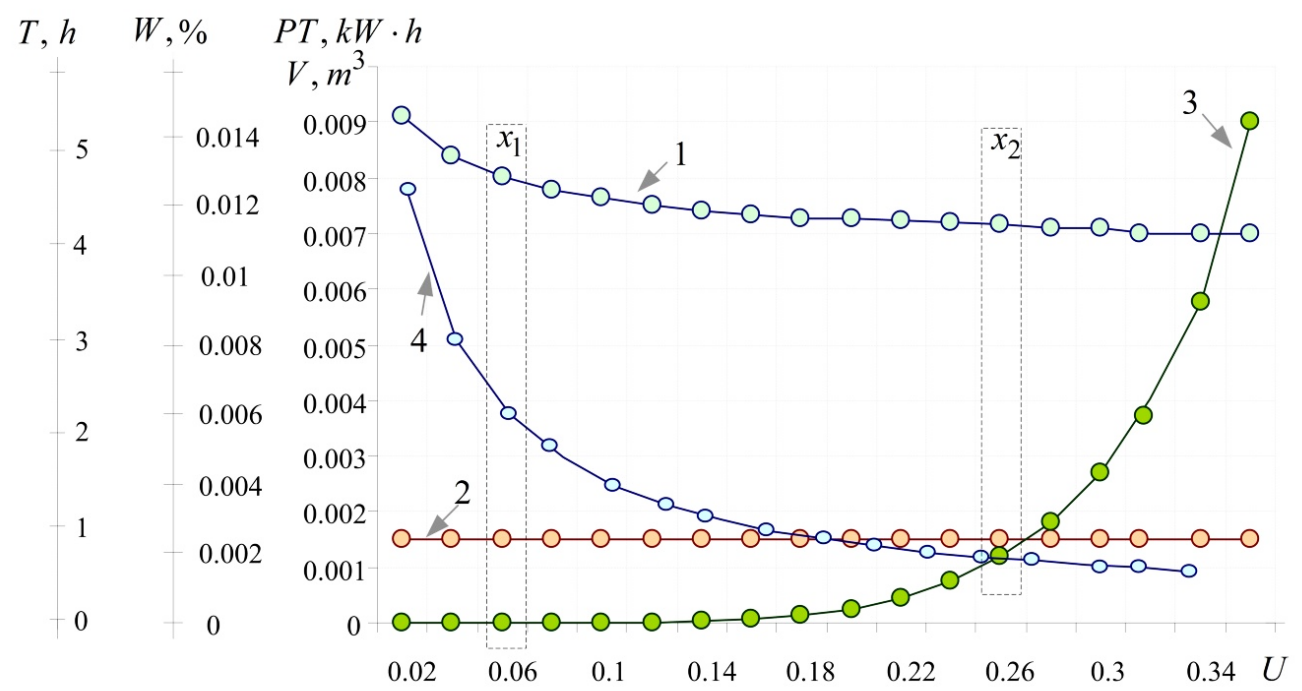

Fig. 2. Diagrams of changing of input and output products parameters of liquid heating operation, depending on the control: 1 - energy consumption; 2 - liquid; 3 - percentage of wear; 4 - operation time 
Analyzing the investigation of functional dependencies, it can be concluded that change in control leads to change in all significant factors of the operational process. In particular, the operation time from control changing is monotonically decreasing function.

This means that each control mode can be identified by its unique set of parameters $\mathrm{U}=$ $=f\left(R Q_{D}, R_{P}, R Q_{W}, P Q_{D}, T O\right)$, where $R_{D}$ - the volume of product of directed action, $R_{P}-$ the volume of energy consumption during the operation time, $\mathrm{RQ}_{\mathrm{W}}-$ level wear of system mechanism during the operation, $\mathrm{PQ}_{\mathrm{D}}$ - the volume of output product of directed action, $\mathrm{TO}$ - operation time.

Using the data in Fig. 2, it is impossible to make judgments about the quantitative evaluation of resources use efficiency of operations $\mathrm{x}_{1}$ and $\mathrm{x}_{2}$, since the units of measurement of the input and output products of these operations are incomparable.

Any operation is carried out in order to increase the value of output products in relation to the value of input products. Therefore, the quality of quantitative parameters reduction coefficient in operational process, it is necessary to use expert or cost estimates.

\section{2. Investigation of possibility to estimate the operations efficiency using parameters of sim- ple general operation model}

The creation of general operation model is presented in works [18-21].

If distributed in time input and output products operation parameters can be neglected, the model should be represented by triple: IRE - input operation products expert evaluation, IPE - output operation products expert evaluation, $\mathrm{TO}$ - operation time. These parameters are obtained by integrating the input and output functions.

As change of qualitative and/or quantitative parameter of any input product leads to change of input function and output function, such functions have to be basis for creation of economical and cybernetic estimated indicators, in particular, of an efficiency indicator.

So, the researches connected with reliability of operations efficiency assessment have to be directed to class of indicators which structure leans on the three (IRE, TO, IPE). Let's define operations models in the form of three (IRE, TO, the IPE) as simple general operations models. As by means of three such objects it is possible to characterize system operation from the point of view of character of resources consumption and resources return, it is defined that IRE, TO, IPE are formal signs of efficiency formula.

The conducted researches show that formation of conclusions about the effectiveness of studied operation under investigation is possible only if the quantitative parameters of input and output products are given in the form of comparable cost values.

This in turn means that the inputs of optimal controlled system (Fig. 3) need to be transmitted as information signals of cost estimates of input and output technological products.

Where RDS - product of directed action cost estimate set section; RPS - energy product cost estimate set section; RWS - each percent of heater's wear cost estimate set section; PDS - input product cost estimate set section; IRE - total input product cost estimate issuing section; IPE - total output product cost estimate issuing section.

Distinctive feature of this model is existence of sections introduction of cost units of input and output technological products [RDS, RPS, RWS, PDS] and also their total cost estimates sections [IRE, IPE].

Results of the model's start are represented in Fig. 4.

Using the concept of the general operation model makes it possible to get results of the operating activity of controlled system in such way that it allows making judgments about the effectiveness of operations using the axiomatic approach.

Thus, it can be argued that operations in the control area $U=0.04 \div 0.32$ are effective. Operation with control $U=0.34$ is inefficient. It can also be argued that the operation is more effective than the operation.

Since the input and basic products of the general operation model can be compared with each other and the data structure does not depend on the individual characteristics of the particular system process, it is possible to put forward the hypothesis that a cybernetic law in the form of an efficiency formula can be expressed using objects of the general operation model. 


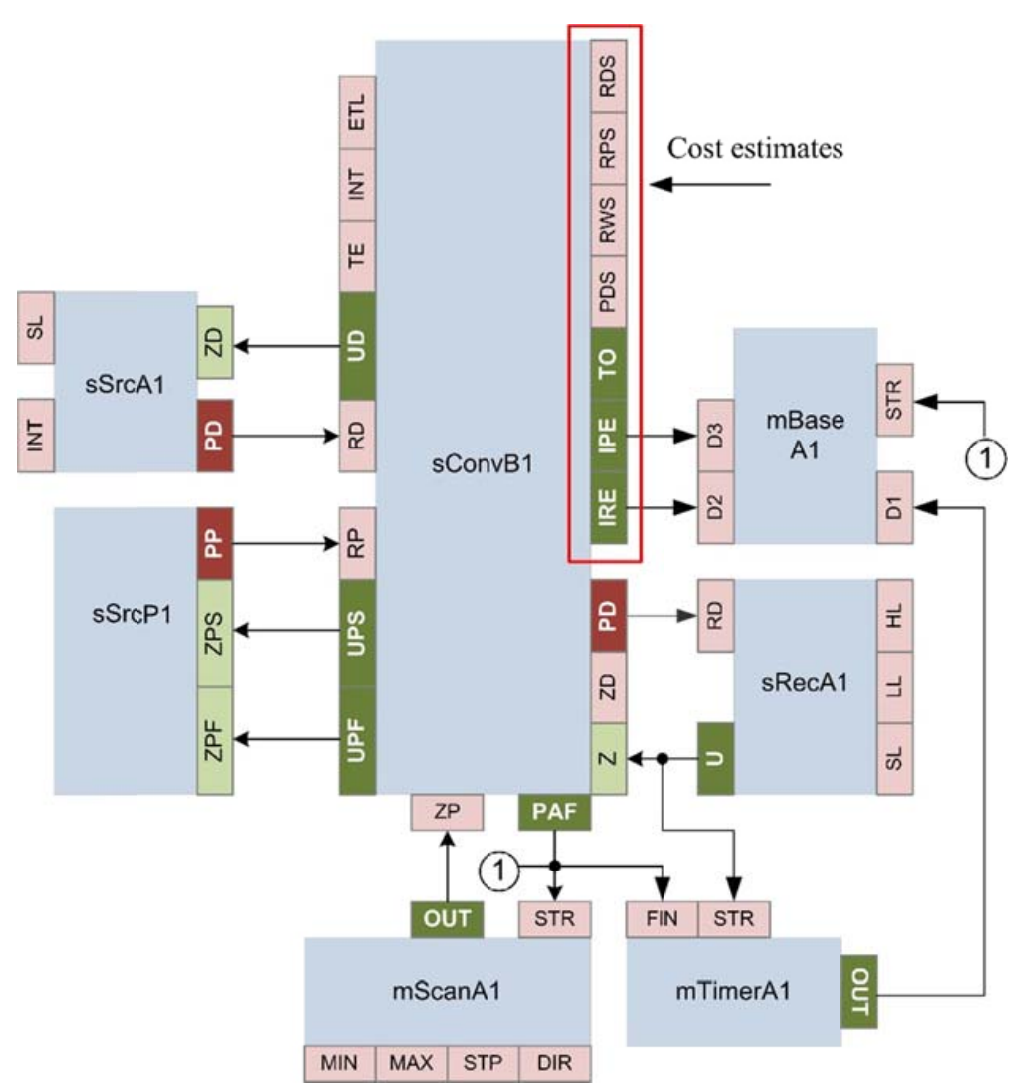

Fig. 3. Model of the economical and cybernetic controlled system

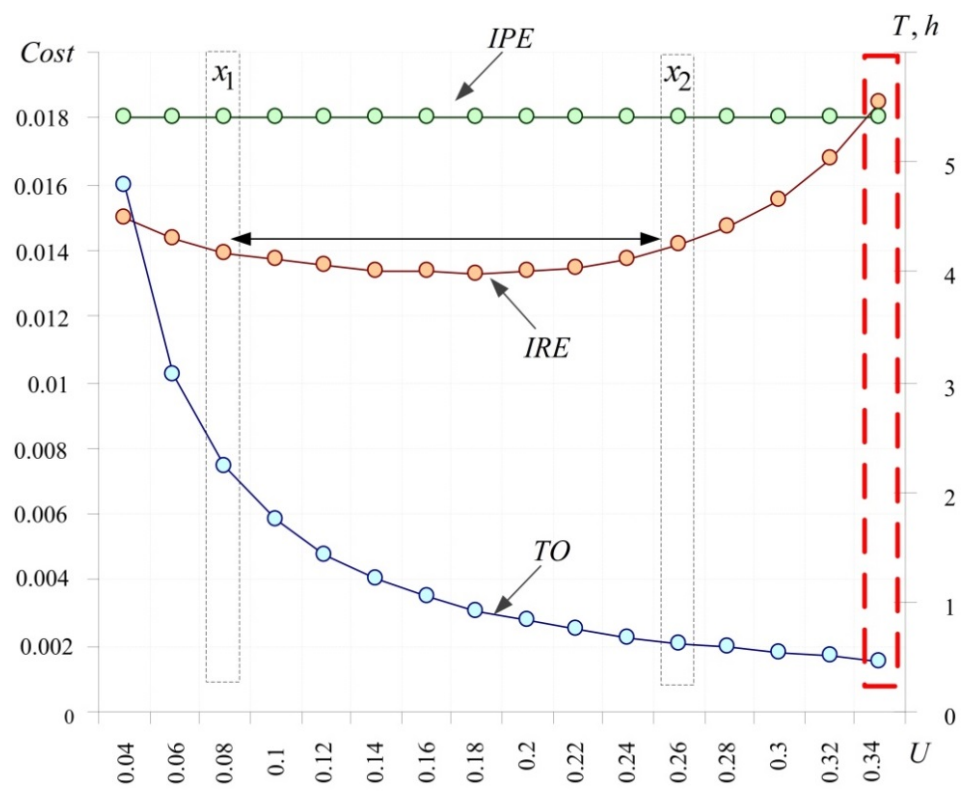

Fig. 4. Change of simple general operation model parameters on control

\section{Results}

Let's choose from many indicators those that correspond to the parameters of general operation model.

It is value added coefficient $\mathrm{ER}=(\mathrm{IPE}-\mathrm{IRE}) / \mathrm{IRE}$, indicator [22] which determines rates of accumulation of operation value added in time $\mathrm{EC}=(\mathrm{IPE}-\mathrm{IRE}) / \mathrm{TO}$, and also indicators $\mathrm{R}=$ $=(\mathrm{IPE}-\mathrm{IRE}) / \mathrm{IRE} * \mathrm{TO}[23], \mathrm{EL}=(\mathrm{IPE}-\mathrm{IRE})^{2}{ }_{*} \mathrm{~T}_{1}{ }^{2} / \mathrm{IRE}^{*} \mathrm{IPE}^{*} \mathrm{TO}^{2}$ [24]. 
Having estimated a set of the general simple operations applying the indicators (ER, EC, R, EL), it is possible to see that each of them has the form and the extremum (Fig. 5).

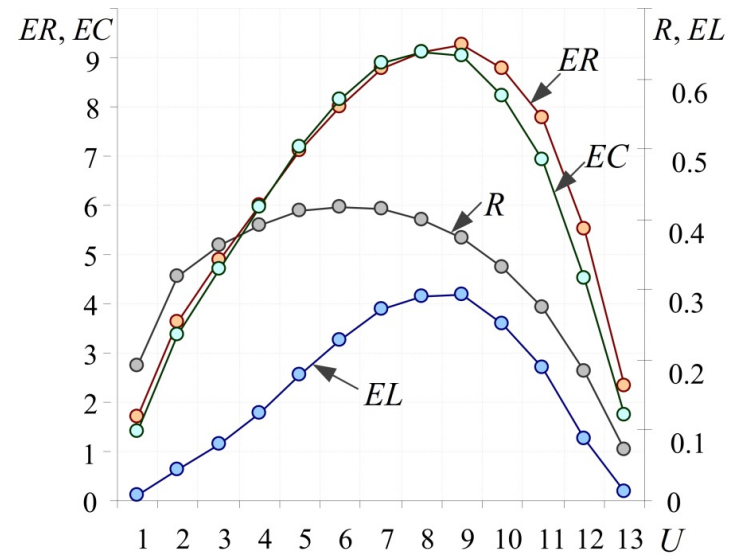

Fig. 5. Charts of extrema of the estimated indicators functions

Thus, there is a scientific problem of verification of an efficiency original indicator among estimated indicators which parameters are based on the three (IRE, TO, IPE) of the general model of operation.

\section{Discussion}

Each of the indicators given above characterizes this or that part of the studied operation. However, within this research, that assessment indicator is of interest which is pointer to an advantageous operation for owner of operational process results.

This indicator reflects the natural cybernetic law which is defined as "an efficiency indicator" or "resources efficiency indicator". Theoretically, the maximum value of this indicator indicates that operation which cycle of performance will provide maximizing financial potential, the controlled system is capable to provide.

\section{Conclusions}

During the conducted researches it is established that:

1. Any system operation can be presented in the form of the general cybernetic or economical and cybernetic model.

2. As function of time has monotonously decreasing character, parameters of the general model of operation (cost assessment of input operation products, cost estimates of output operation products and operation time) provide its unambiguous identification.

3. On the basis of comparison of parameters of the general operation model, there is an opportunity to form conclusions concerning resources efficiency of system operations. It means that the cybernetic law defining assessment of resources efficiency can be submitted by efficiency formula (E). At the same time the structure of the efficiency formula in general view can be presented in the form of dependence of $\mathrm{E}=\mathrm{f}$ (IRE, TO, IPE).

\section{Acknowledgments}

I express gratitude for the help in concept development and conducting pilot studies to $\mathrm{PhD}$, Professor Igor Lutsenko.

\section{References}

[1] Zhigunova, N. M.; Gerasimovoy, G. E. (Ed.) (2005). Metodologiya uluchsheniya deyatel'nosti organizatsiy na osnove protsessnogo podkhoda. Kachestvo menedzhmentai protsessnyy podkhod. Moscow: OOO «NTK «Trek», 80.

[2] Mikhaylova, E. A. (2002). Osnovy benchmarkinga. Moscow: Yurist, 110. 
[3] Kolocheva, V. V. (2009). Otsenka effektivnosti protsessov predpriyatiya s ispol'zovaniem protsessnogo benchmarkinga. Molodoy uchenyy, 10, 147-151.

[4] Lutsenko, I. A. (2014). A practical approach to selecting optimal control criteria. Technology Audit and Production Reserves, 2 (1 (16)), 32-35. doi: 10.15587/2312-8372.2014.23432

[5] Kurganov, I. D. (2007). Optimal'noe upravlenie tekhnologicheskim protsessom transportirovaniya rudnoy massy putem izmeneniya natyazheniya lenty. Razrabotka rudnykh mestorozhdeniy, 91, 199-203.

[6] Basin, M., Jimenez-Lizarraga, M., Rodriguez-Ramirez, P., Rodriguez-Carreon, C. (2013). Optimal control for a polynomial system with a quadratic criterion over infinite horizon. International Journal of Systems Science, 1-12. Available at: http://www.tandfonline.com/doi/abs/10.1080/00207721.2013.823528\# preview/ doi: 10.1080/00207721.2013.823528

[7] Nazarenko, N. V., Ladigina, G. O. (2008). Vibir KIS pidpriemstva: kriterii efektivnosti (optimal'nosti). Visnik Krivoriz'kogo tekhnichnogo universitetu, 21, 135-139.

[8] Yurchenko, V. A., Bakhareva, A. Yu. (2011). Otsenka effektivnosti raboty fil'tra iz aktivirovannogo uglya degazatora pri ochistke gazoobraznykh vybrosov iz kanalizatsionnykh setey ot metana. Vestnik NTU «KHPI», 53, 39-44.

[9] Den'gub, V. I., Lapshin, A. A., Fedorov, D. B. (2007). Otsenka effektivnosti okhlazhdeniya zaboynoy ventilyatsionnoy strui szhatym vozdukhom. Razrabotka rudnykh mestorozhdeniy, 91, 245-248.

[10] Udovenko, O. A. (2007). Kompleksnyi podkhod k povysheniyu effektivnosti modernizatsii elektroprivodov. Razrabotka rudnykh mestorozhdeniy, 91, 151-155.

[11] Mihajlovic, I., Strbac, N., Dordevic, P., Ivanovic, A., Zivkovic, Z. (2011). Technological process modeling aiming to improve its operations management. Serbian Journal of Management, 6 (2), 135-144. doi: $10.5937 / \mathrm{sjm} 1102135 \mathrm{~m}$

[12] Serdiuk, O. (2015). Criterion of identification of test steps in training and educational systems. Metallurgical and Mining Industry, 9, 605-608.

[13] Serdiuk, O. (2016). Development of criterion for comparative assessment of executive systems functional actvity. Technology Audit and Production Reserves, 4 (3 (30)), 40-46. doi: 10.15587/2312-8372.2016.74866

[14] Morkun, V., Tron, V. (2014). Ore preparation multi-criteria energy-efficient automated control with considering the ecological and economic factors. Metallurgical and Mining Industry, 5, 4-7.

[15] Zheng, Y.-J., Ling, H.-F., Xue, J.-Y. (2014). Ecogeography-based optimization: Enhancing biogeography-based optimization with ecogeographic barriers and differentiations. Computers \& Operations Research, 50, 115-127. doi: 10.1016/j.cor.2014.04.013

[16] Lutsenko, I. A., Nikolaenko, N. I. (2011). Synthesis of change authority to regulate development environment controlled systems EFFLY. Technology Audit and Production Reserves, 2 (2 (2)), 20-23. doi: $10.15587 / 2312-8372.2011 .4861$

[17] Dropbox. Available at: https://www.dropbox.com/home/Efficiency?preview=MODEL_1.xls

[18] Lutsenko, I., Fomovskaya, E., Koval, S., Serdiuk, O. (2017). Development of the method of quasioptimal robust control for periodic operational processes. Eastern-European Journal of Enterprise Technologies, 4 (2 (88)), 52-60. doi: 10.15587/1729-4061.2017.107542

[19] Lutsenko, I., Fomovskaya, E., Oksanych, I., Vikhrova, E., Serdiuk, O. (2017). Formal signs determination of efficiency assessment indicators for the operation with the distributed parameters. EasternEuropean Journal of Enterprise Technologies, 1 (4 (85)), 24-30. doi: 10.15587/1729-4061.2017.91025

[20] Serdiuk, O. (2016). Development of criterion for comparative assessment of executive systems functional actvity. Technology Audit and Production Reserves, 4 (3 (30)), 40-46. doi: 10.15587/2312-8372.2016.74866

[21] Lutsenko, I., Vihrova, E., Fomovskaya, E., Serdiuk, O. (2016). Development of the method for testing of efficiency criterion of models of simple target operations. Eastern-European Journal of Enterprise Technologies, 2 (4 (80)), 42-50. doi: 10.15587/1729-4061.2016.66307

[22] Tsirlin, A. M. (1986). Optimal'noe upravlenie tekhnologicheskimi protsessami. Moscow: Energoatomizdat, 400 .

[23] Lutsenko, I. A., Serdyuk, O. Yu., Fomovs'ka, O. V. (2016). Razrabotka dinamicheskoy modeli ekonomicheskoy operatsii. Nauchnye issledovaniya. Moscow: RusAl'yans Sova, 77-78.

[24] Lutsenko, I. (2015). Identification of target system operations. development of global efficiency criterion of target operations. Eastern-European Journal of Enterprise Technologies, 2 (2 (74)), 35-40. doi: $10.15587 / 1729-4061.2015 .38963$ 